\title{
Action plans and coping plans for physical exercise: A longitudinal intervention study in cardiac rehabilitation
}

\author{
Falko F. Sniehotta ${ }^{\prime}$, Urte Scholz ${ }^{2}$ and Ralf Schwarzer ${ }^{2}$ \\ 'University of Aberdeen, UK \\ ${ }^{2}$ Free University of Berlin, Germany
}

\begin{abstract}
Objectives. The aim of the present study was to test two brief planning interventions designed to encourage cardiac patients to engage in regular physical exercise following discharge from rehabilitation. The interventions comprised action plans on (a) when, where, and how to act, and (b) coping plans on how to deal with anticipated barriers.

Design and method. An experimental longitudinal trial was conducted to test two interventions that either focused on action planning alone, or on a combination of action planning and coping planning. A total of 211 participants completed assessments at baseline and 2 months after discharge. Participants were randomly assigned to either one of the intervention groups or a standard-care control group.

Results. Participants in the combined planning group did significantly more physical exercise 2 months post-discharge than those in the other groups.

Conclusions. The theoretical distinction between action planning and coping planning as introduced in the present study has proven useful in explaining changes in health-related behaviour. The combined planning intervention can be applied in the context of cardiac rehabilitation programmes.
\end{abstract}

The adoption and maintenance of health behaviours such as physical exercise have been studied in terms of goal setting and goal pursuit. While the former reflects an initial motivation process, the latter refers to self-regulation when it comes to translating a health goal into action. In this second phase, planning has proven useful. The present study addresses this particular issue by experimentally inducing two kinds of planning, labelled action planning and coping planning for improving adherence with prescribed exercise recommendations in patients discharged from cardiac rehabilitation.

* Correspondence should be addressed to Dr Folko F. Sniehotta, University of Aberdeen, School of Psychology, College of Life Sciences and Medicine, King's College, William Guild Building, Aberdeen AB24 2UB, UK (e-mail: f.sniehotto@abdn.ac.uk). 


\section{Physical activity in cardiac rehabilitation}

Regular aerobic physical activity plays a crucial role in the prevention and rehabilitation of coronary heart disease (CHD). Physical exercise refers to physical activities that are 'planned, structured, repetitive, and purposeful in the sense that improvement or maintenance of physical fitness is the objective' (Thomson et al., 2003, p. 3109). Several studies have identified a positive relationship between a sedentary lifestyle and incidences of CHD (cf. Paffenbarger, Hyde, Wing, \& Hsieh, 1986). While some of these studies suggest only vigorous exercise to be protective (cf. Lakka et al., 1994; Morris, Everitt, Pollard, \& Chave, 1980), other research also provides evidence for the usefulness of everyday physical activities such as gardening or cycling (Leon, Connett, Jacobs, \& Rauramaa, 1987; Magnus, Matroos, \& Strackee, 1979). A linear relationship between energy conversion and decreasing CHD risk has been found. Vigorous exercise for at least 30 minutes three times a week or better on a daily basis is recommended to prevent CHD (Pate et al., 1995).

In rehabilitation, exercise reduces symptoms in $\mathrm{CHD}$ patients and is associated with a lower mortality (Oldridge, Guyatt, Fischer, \& Rimm, 1988; O'Connor et al., 1989). Physical exercise is therefore an essential part of cardiac rehabilitation programmes (World Health Organization, 1993). Furthermore, a major aim of such programmes is to motivate patients to maintain regular exercise after discharge.

Despite the high-risk status of CHD patients and recommendations given during their rehabilitation treatment, a sedentary life-style is difficult to change (Johnston, 1999; Marcus et al., 2000). Only 25\% of cardiac rehabilitation patients adhere to the prescribed training programme 1 year following discharge (Willich et al., 2001).

Patients diagnosed with CHD have often led a habitual sedentary lifestyle for years (Campbell, Thain, Deans, Ritchie, \& Rawles, 1998). Habitual behaviour is strongly controlled by environmental cues that almost automatically trigger behavioural acts (Ronis, Yates, \& Kirscht, 1989). Habitual behaviour patterns are, therefore, usually very stable and resistant to change even if they are contradictory to one's intentions, especially when no routines for alternative activities such as physical exercise are at hand (see Sutton, 1994).

\section{Psychological predictors of changes in health behaviours}

To analyse how changes of habitual behaviour patterns can be facilitated, a distinction between a motivational phase and a volitional phase has been proposed (Heckhausen, 1991; Schwarzer, 1992). In the motivational phase, a person develops an intention to change his or her behaviour. In the volitional phase, the intended change must be planned, initiated, and maintained. The starting-point for the motivational phase is often some level of risk awareness, for example, feeling vulnerable to a (recurring) cardiac event. Positive and negative outcome expectancies for regular exercise are deliberated. If the pros outweigh the cons of a behavioural change, one prerequisite for an intention is accomplished. Perceived selfefficacy (Bandura, 1997), that is, the perceived capability to implement successfully alternative behaviours, along with outcome expectancies and risk awareness is seen as an influential factor of the intention formation (Schwarzer, 1992). Behavioural intentions (Ajzen, 1991) direct motivation towards a target behaviour. Reviews conclude that on average $20-30 \%$ of the variance in behaviour can be accounted for by intentions (Conner \& Armitage, 1998; Sheeran, 2002). With respect to changes in habitual life-styles, such as starting and maintaining a recommended training programme by formerly sedentary individuals, the intention-behaviour association might be even weaker because 
individuals fail to overcome old habits (Sutton, 1994). This 'gap' between intentions and behaviour can be ascribed to inclined abstainers; individuals who intend to act, but fail to implement their intentions (Orbell \& Sheeran, 1998; Sheeran, 2002). These failures can be attributed to a lack of appropriate self-regulatory strategies (Abraham, Sheeran, \& Johnston, 1998). One of these strategies is planning.

\section{The role of planning in health behaviour change}

In the present article, we argue that planning can be divided into two subconstructs that serve different purposes. The first subconstruct, action planning, specifies the intended action in terms of when, where, and bow to act (e.g. Leventhal, Singer, \& Jones; 1965). Gollwitzer (1999) has called this implementation intentions. The second subconstruct, coping planning, alludes to coping strategies to prioritize the intended over the habitual responses when obstacles or barriers are faced.

Action planning is defined as a post-intentional process that links goal-directed responses to situational cues by specifying when, where, and how to act in accordance with one's goal intention. People who form such action plans are more likely to act in the intended way and initiate the goal behaviour faster (Gollwitzer \& Oettingen, 1998; Orbell \& Sheeran, 2000). Intentions are precursors of action planning. The effects of planning are moderated by intentions (Gollwitzer \& Oettingen, 1998; Orbell, Hodgkins, \& Sheeran, 1997). The beneficial effects of action planning have been shown for different health-behaviour domains, such as cervical cancer screening (Sheeran \& Orbell, 2000), conducting breast self-examination (Luszczynska \& Schwarzer, 2003), reduction of dietary fat intake (Armitage, 2004), and pursuing physical activity (Milne, Orbell, \& Sheeran, 2002; Sniehotta, Scholz, \& Schwarzer, 2005). None of these studies reported gender or age differences. A recent meta-analysis provides compelling evidence that forming prospective if then plans has positive effects of medium to large effect size on goal pursuit over 94 tests with participants of different age and gender (Gollwitzer \& Sheeran, in press).

Coping planning is conceptualized as an independent planning cognition that prepares a person for successful coping with situations in which strong cues invite both unintended responses (e.g. habits) and intentional responses (e.g. newly planned actions, Sniehotta, Schwarzer, Scholz \& Schüz, 2005). Anticipating such situations allows for proactive preparation of strategies that aim to prioritize the intended behaviour. Those strategies can consist of self-regulatory techniques, such as self-instructed motivation statements, cognitive restructuring, emotion control, techniques for handling the situation, or escape responses (e.g. Baumeister, Heatherton, \& Tice, 1994).

Coping planning has similarities to classical techniques in cognitive behavioural therapy that aim at developing coping skills through anticipatory practice, such as pre-hearsal (Kanfer, 1979). In contrast to therapeutic approaches, coping planning is based on the assumption that the self-regulatory coping responses necessary are already at the disposal of the person, relying on prior experience and resulting from the rehabilitation treatment. Likewise, it is assumed that individuals are capable of recognizing cues related to the execution of unwanted behaviour in their everyday life. Based on these assumptions, coping planning consists of the pairing of anticipated risk situations and coping responses (Sniehotta, Schwarzer et al., 2005; Ziegelmann, Lippke \& Schwarzer, in press). Examples for coping plans are: 'If I want to go swimming, but I am tired, I will not let myself sit down, but will go to the swimming pool at once', or 'If I am not motivated to start my scheduled training programme, I will think about my health to motivate myself.' 
Coping planning differs significantly from action planning in both the situational and the behavioural components. Situational cues associated with action plans are located in the individual's environment and are defined by 'where and when' to act. Coping plans are ideographically defined by situations with conflicting behavioural tendencies and are consequently embedded in the person-environment interaction. The behavioural (or cognitive) response to a coping plan is not necessarily goal-related (e.g. thinking about one's health is not directly related to physical activity), but it presumes the existence of an action plan. Therefore, both action planning and coping planning are supposed to promote goal attainment in orchestration. They jointly establish a roadmap to action by specifying the details of action implementation as well as ways of successful coping with adversity.

\section{Aims and hypotheses}

This study examines the long-term effectiveness of two planning interventions, based on (a) action planning, and (b) action planning combined with coping planning. These two interventions aim to increase physical activities of $\mathrm{CHD}$ patients in rehabilitation. The following hypotheses were tested:

(1) The action planning intervention will increase physical exercise 2 months following discharge.

(2) The combined action planning and coping planning intervention will lead to higher levels of physical exercise than either in the control group or in the action planning group.

(3) No gender and age effects of the planning interventions will occur.

(4) The planning interventions will not have an effect on behavioural intentions. Intentions are regarded as motivational precursors of planning

\section{Method}

\section{Sample details}

The sample comprised 246 patients with CHD who underwent a 3 week residentiallybased cardiac rehabilitation treatment (see Table 1 for demographic profile). Inclusion criteria for the study were diagnosed $\mathrm{CHD}$ and medical recommendation to engage in regular vigorous physical training after discharge. Exclusion criteria were conditions under which physical exercise should not be implemented without supervision.

The rehabilitation treatment addressed changing behavioural risk factors in terms of somatic and psychoeducational measures (Dietz \& Rauch, 2003). All patients attended at least three to five times a week to do vigorous exercise such as bicycle ergometer training with individualized strain levels as well as three to five sessions of walking. Furthermore, they participated in group or individual aerobic exercises and in some cases weight training (Bjarnason-Wehrens, Mayer-Berger, Meister, Hambrecht, \& Gielen, 2004). Participants were recommended to engage in regular vigorous exercise after discharge, such as bicycle-ergometer training, swimming, or running at least three times per week for a minimum of 30 minutes per unit. Furthermore, they were advised to increase their everyday physical activities, for example, by using a bicycle instead of car or public transportation. In order to increase compliance to these recommendations, attitudes, knowledge about CHD and its rehabilitation and motivation were addressed in psychoeducational classes (Dietz \& Rauch, 2003). 
Table I. Demographic characteristics of the final sample and $\chi^{2}$ tests for differences between the final sample and drop-outs

\begin{tabular}{lcccc}
\hline Variable & Sample & Drop out & & \\
& $N(\%)$ & $N(\%)$ & $\chi^{2}$ & $P$ \\
\hline Marital status & & & 5.03 & .17 \\
Married/common law & $172(81.5)$ & $23(65.7)$ & & \\
Divorced/separated & $15(7.1)$ & $3(8.6)$ & & \\
Single & $15(7.1)$ & $5(14.3)$ & & \\
Widowed & $7(3.3)$ & $3(8.6)$ & & \\
Not specified & $2(0.9)$ & $1(2.9)$ & \multirow{2}{*}{0.53} & .77 \\
Education level & $70(33.2)$ & $9(25.7)$ & & \\
Grade 9 or less & $63(29.9)$ & $11(31.4)$ & & \\
High school & $75(35.5)$ & $13(37.1)$ & & \\
Post-secondary & $3(1.4)$ & $2(5.7)$ & \multirow{2}{*}{0.17} & .68 \\
Not specified & $96(45.5)$ & $15(42.9)$ & & \\
Employment status & $127(60.2)$ & $16(45.7)$ & & .20 \\
Employed & $16(7.6)$ & $5(14.3)$ & & \\
Diagnosis on admittance & $68(32.2)$ & $14(40.0)$ & & \\
Myocardial infarction & & & \\
Bypass surgery & $25(11.8)$ & $7(20.0)$ & & \\
Angioplasty & $57(27.0)$ & $7(20.0)$ & & \\
Smoking status & $125(59.2)$ & $21(60.0)$ & & \\
Currently smoking & & & \\
Never smoked & & & \\
Quit & & & & \\
& & & & \\
\end{tabular}

The physicians of the cooperating centres made appointments for the first contact. In the second week at the rehabilitation centre, patients were invited by members of the research team to participate in the study. They were informed about the study and were assured confidentiality of all medical and psychological data. Furthermore, they were informed that the participation was voluntary und unpaid. All participants were treated in accordance with the American Psychological Association ethical guidelines (APA, 2002).

\section{Study design and procedure}

A longitudinal trial was conducted over a 10 -week period. The first measurement was taken in the second week of the rehabilitation programme (Time 1) and the second measurement was sent to the patients 2 months after discharge (Time 2), with a stamped addressed envelope. After Time 1, participants were randomly assigned to one of two treatment groups or to a control group. Participants in the two treatment groups were invited to take part in an individual planning session during the last week of their stay in the clinic.

\section{Measures}

At Time 1, risk perceptions, outcome expectancies, self-efficacy, behavioural intentions, past cycling and past exercise were assessed. At Time 2, behavioural intentions, cycling and physical exercise were assessed. Information on age, gender, marital status, education level, employment status, diagnosis on admittance, and smoking status were taken from the medical file with the permission of the patients. 
Risk awareness, outcome expectancies, self-efficacy, and intentions were measured, using the same techniques as Schwarzer and Renner (2000). The item examples below are translations from German. Unless otherwise stated, all items had a response range from 1 (not at all true) to 4 (exactly true). Risk awareness was assessed by four items, $\alpha=.93$, with the stem: 'If I keep my life-style the way it was prior to the acute treatment ..., followed by four statements concerning probable future coronary events, for example, ' . I I would suffer from coronary health problems'. Outcome expectancies were measured as positive (pros) and negative outcome expectancies (cons) of adhering to a regular training programme. The stem 'If I exercise regularly . . .' was completed by four possible cons, $\alpha=.77$, such as '. . then I will need to invest a lot of effort to organize it', and eight possible pros, $\alpha=.75$, such as '. .then I will prevent a cardiac event', or '. . . then I will be less vulnerable for disease'.

The self-efficacy scale was composed of six items, $\alpha=82$. All items commenced with the stem 'I am certain that I can. . ' and were followed by the recommended activities, such as 'be regularly physically active for a minimum of 30 minutes at least three times a week'. Bebavioural intentions were assessed for the time after discharge. Participants were asked to reply to six intentional statements regarding exercise and other physical activities. The stem 'I intend to. . ' was followed by the recommended activities, for example, '. . . be regularly physically active for a minimum of 30 minutes at least three times a week.' The scale yielded a Cronbach's $\alpha$ of .79 .

To assess physical exercise at Time 1 , patients were asked how often they engaged in a list of activities in the month prior to the acute cardiac event. The same was repeated 2 months after discharge (Time 2) with respect to the last month. The list of activities contained endurance sports such as swimming, running, power walking, bike racing, biking, and so on, physical activities such as callisthenics and dancing, and other physical exercises recommended by health professionals. Patients indicated how often they engaged in one of these activities per week and how many minutes an average unit lasted. Bernstein and colleagues (1998) reported a similar approach. The time engaged in these activities was computed as a sum score of exercise in minutes (multiplying the frequency with the reported minutes per unit). Using the bike instead of the car or public transportation for everyday activities was assessed in the same way as an example for a non-scheduled everyday activity.

\section{Planning interventions}

Participants received a planning sheet and were asked to follow the instructions on the sheet. In the action planning group, participants formed up to three action plans about when, where, and how they intended to exercise and/or intended to implement extra everyday physical activities after discharge. In the combined planning group, participants additionally formed up to three coping plans about strategies to overcome anticipated barriers. All treatments were conducted by trained consultants in a oneto-one setting and lasted up to 30 minutes. The consultants were trained to guide the planning session in a nondirective manner. Patients wrote down all plans on a planning sheet that was handed in afterwards. In case of questions or misunderstandings, they were invited to ask the consultants.

The planning sheet for action plans started with the instruction, 'Please think about the time after discharge from the rehabilitation centre. When, where and how do you plan to be physically active? Please write down your plans in the following table. The more precise, concrete and personally you formulate your plans, the more they can 
help you: The table contained three rows labelled Plan 1, Plan 2, and Plan 3. The columns were headed with 'when', 'where', 'how', and 'with whom'.

The planning sheet for coping plans started with the instruction: "Which obstacles or barriers might interfere with the implementation of your exercise plans? How could you successfully cope with such problems? Please write down your plans in the following table. The more precise, concrete and personally you formulate your plans, the more they will help you.' Both planning sheets ended with the statement, 'memorize your plans carefully. Visualise the situations and your planned actions and make a firm commitment to act as planned.'

\section{Results}

\section{Drop-out analyses}

Out of the initial 246 participants, 217 completed a questionnaire by mail at Time 2 . Six participants who returned their questionnaire 2 months after receipt were excluded from the study. For the other participants, the average time between receiving questionnaires and returning them was 10.8 days $(S D=13.4)$. Thus, the final data analyses are based upon 211 participants ( $88 \%$ of the initial sample). Of these, 46 patients were women (22\%) and 165 were men. Participants' mean age was 59.3 years $(S D=10)$ and ranged from 31 to 82 years. Table 1 displays the demographic and medical characteristics of the participants included in the final analysis and of those who were not included.

The 35 patients who dropped out did not differ from the others with respect to the variables listed in Table 1 using $\chi^{2}$ tests. Likewise, one-way ANOVAs revealed no significant differences for risk awareness, $F(1,244)=2.08, p=.15 ;$ pros, $F(1,244)=0.42, p=.52$; cons, $F(1,244)=1.24, p=.27$; self-efficacy, $F(1,244)=0.79$, $p=.38$; behavioural intentions, $F(1,244)=3.05, p=.08$; past exercise $F(1,244)=2.76$, $p=.10$, and past cycling, $F(1,244)=0.16, p=.69$.

\section{Randomization checks}

Cell sizes of the three experimental groups turned out to be unequal due to the randomization procedure. Each consultant assigned participants to experimental conditions according to an assignment-sheet that followed the order control group, action planning group, combined planning group. Thus, each consultant who saw a number of patients that is not divisible by 3 contributed to initially unequal group sizes (control group, $N=94$, action planning group, $N=81$, combined planning group, $N=71$ ). Furthermore, some patients in the planning groups dropped out of the sample before giving informed consent, because time for the planning intervention could not be found due to other activities in the rehabilitation centre.

Table 2 presents Time 1 mean values and standard deviations for social-cognitive predictors and exercise behaviour. ANOVAs conducted to test for group differences revealed no pre-interventional differences on measures of risk awareness, pros, cons, self-efficacy, intentions, and past behaviour. Likewise, the groups did not differ in gender proportions, $\chi^{2}=1.67, n s$, and no age differences were observed, $F(3,208)=0.78, n s$. It can be concluded that potential differences between the groups at Time 2 cannot be attributed to baseline differences.

Table 2 indicates that, in general, patients had strong intentions to engage in regular physical activities after discharge, with mean scores higher than 3 on a scale ranging from 1 to 4. Similarly, motivational variables such as risk awareness, pros, and self-efficacy show 
Table 2. Means and standard deviations for social-cognitive predictors and past activities in control action planning and combined planning groups

\begin{tabular}{lccccc}
\hline & $\begin{array}{c}\text { Control group } \\
N=81\end{array}$ & $\begin{array}{c}\text { Action planning group } \\
N=68\end{array}$ & $\begin{array}{c}\text { Combined planning group } \\
N=62\end{array}$ & $F(2,208)$ & $P$ \\
\hline Risk awareness & $3.02(0.75)$ & $3.05(0.88)$ & $3.15(0.84)$ & 0.47 & .62 \\
Pros & $3.42(0.44)$ & $3.50(0.40)$ & $3.48(0.44)$ & 0.85 & .43 \\
Cons & $1.85(0.67)$ & $1.83(0.67)$ & $1.81(0.69)$ & 0.07 & .93 \\
Self-efficacy & $3.35(0.62)$ & $3.37(0.52)$ & $3.29(0.66)$ & 0.35 & .71 \\
Intentions & $3.40(0.51)$ & $3.45(0.51)$ & $3.40(0.51)$ & 0.18 & .84 \\
Past exercise & $55.03(104.15)$ & $70.38(144.90)$ & $69.06(157.80)$ & 0.30 & .74 \\
Past cycling & $52.47(112.86)$ & $44.79(126.45)$ & $63.61(145.29)$ & 0.36 & .70 \\
\hline
\end{tabular}

Note. Standard deviations are in parentheses. $F$ and $p$ values are based on ANOVAs. 'Past exercise' refers to minutes of exercising based on all activities presented. Past cycling refers to minutes of using a bike instead of a car or the public transport system.

high values, while cons show rather low values, with mean scores lower than 2 . This indicates a positive motivational background of the patients.

\section{Effects of the interventions}

Table 3 shows means and standard deviations for the exercise performed by the participants in the three groups, the time they spent cycling per week, and behavioural intentions at Time 2. Changes in activity compared with baseline measures were analysed by ANCOVAs, controlling for the baseline behaviour as covariate.

Table 3. Adjusted means (controlled for baseline) and standard errors for exercise, cycling (in minutes) and behavioural intentions

\begin{tabular}{lccccc}
\hline & Control group & Action planning group & Combined planning group & & \\
& $N=81$ & $N=68$ & $N=62$ & $F(2,207)$ & $\eta^{2}$ \\
\hline Exercise & $95.35(12.72)$ & $113.26(13.87)$ & $178.94(14.52)$ & $9.97 * *$ & 0.09 \\
Cycling & $49.37(11.25)$ & $60.37(12.29)$ & $93.96(12.87)$ & $3.56 *$ & 0.03 \\
Intentions & $3.30(0.05)$ & $3.39(0.06)$ & $3.43(0.06)$ & 1.28 & - \\
\hline
\end{tabular}

Note. Standard errors are in parentheses. $* p<.05$, **p $<.01 F$ values and $\eta^{2}$ are based on ANCOVAs controlling for baseline measures of the represented variables. 'Exercise' refers to minutes of exercising based on all activities presented. Cycling refers to minutes of using a bike instead of a car or the public transport system.

The analyses of covariance revealed significant differences between the three groups for exercising and cycling (see Fig. 1), accounting for $9 \%$ and 3\%, respectively, of the change-variance in behavioural measures. No significant differences in change scores for behavioural intentions were observed. The latter result confirms the third hypothesis. For further analyses of Hypotheses 1 and 2, planned group contrasts were conducted. No significant differences between the control group and the action planning group were found, either for exercise, $F(1,146)=1.48, p=.26$, or for cycling, $F(1,146)=0.75$, $p=$.39. Therefore, Hypothesis 1 was rejected. 

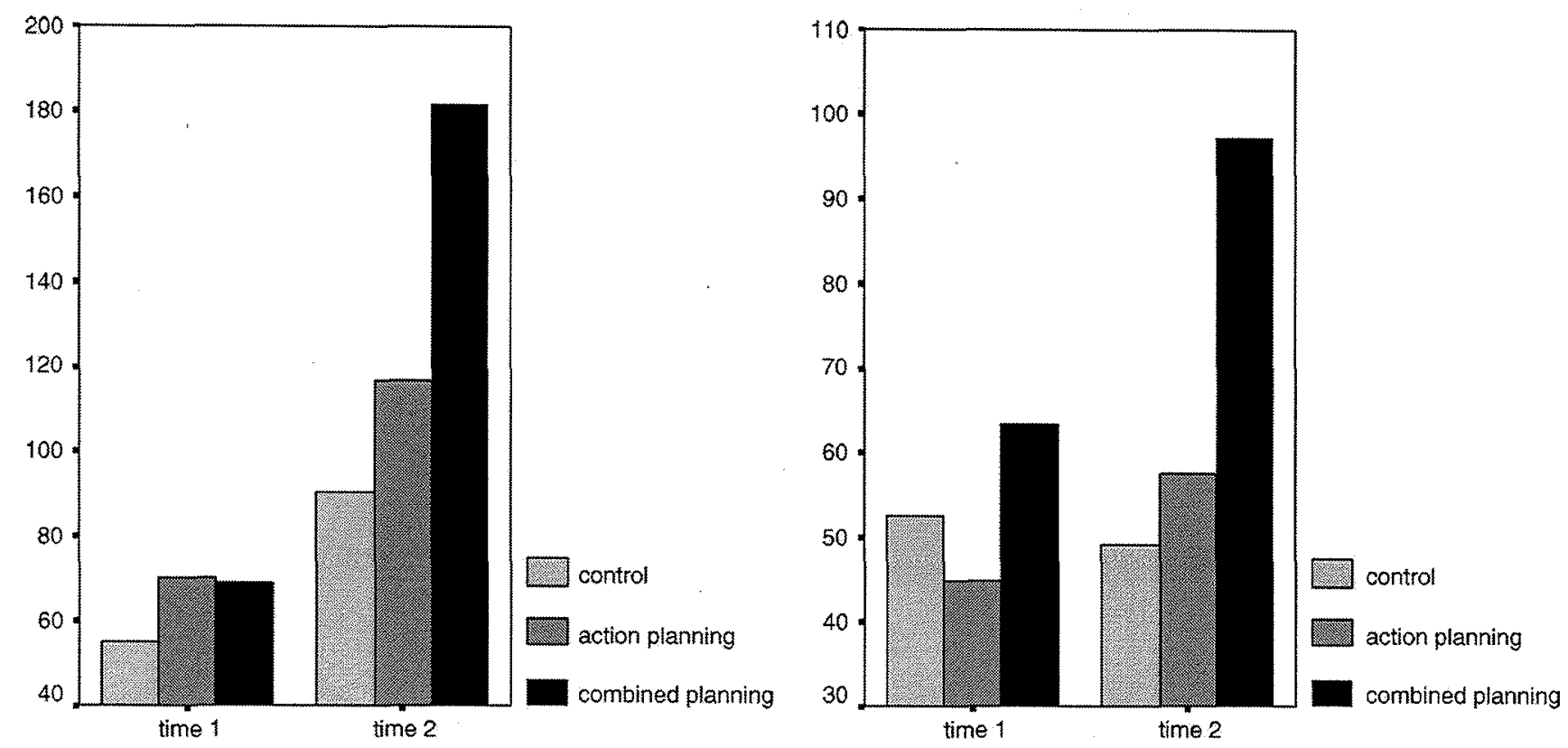

Figure I. Mean values for strenuous physical exercise (left) and cycling (right) at Time I and Time 2 for control group, action planning group, and combined planning group (in minutes per week). 
Participants in the combined planning group differed from those in the control group regarding exercise, $F(1,140)=18.31, p<.01$, and cycling, $F(1,140)=6.38$, $p=.01, \eta^{2}=.12$, and from those in the action planning group regarding exercise, $F(1,127)=8.78, p<.01$. Differences between both treatment groups concerning cycling approached significance, $F(1,127)=3.00, p=.09$. These results support Hypothesis 2.

In further analyses, participants were classified in groups with respect to their adherence at Time 2 to the recommendation to exercise at least three times a week for at least 30 minutes. Three groups of participants were distinguished: completely sedentary participants were defined as those who had not engaged in any exercise. Participants who had engaged in exercise, but who did not attain the recommended minimum of 90 minutes per week were defined as underachievers. Finally, participants who had exercised at least 90 minutes per week were defined as achievers. Table 4 shows the frequencies and percentages of sedentary participants, underachievers, and achievers in the three experimental groups.

Table 4. Frequencies of sedentary participants, underachievers, and achievers within the experimental groups

\begin{tabular}{lccc}
\hline & $\begin{array}{c}\text { Control group } \\
N=81\end{array}$ & $\begin{array}{c}\text { Action planning group } \\
N=68\end{array}$ & $\begin{array}{c}\text { Combined planning group } \\
N=62\end{array}$ \\
\hline Sdentary $(N=56)$ & $27(33.3 \%)$ & $18(26.5 \%)$ & $11(17.7 \%)$ \\
Underachievers $(N=47)$ & $20(24.7 \%)$ & $20(29.4 \%)$ & $7(11.3 \%)$ \\
Achievers $(N=108)$ & $34(42.0 \%)$ & $30(44.1 \%)$ & $44(71.0 \%)$ \\
\hline
\end{tabular}

Note. Column percentages are shown in parentheses. Sedentary: no exercise, Underachievers: $<90$ minutes per week, Achievers: $\geq 90$ minutes per week.

Three $\chi^{2}$ tests were conducted to test whether the proportion of sedentary participants, underachievers, and achievers differed in the three groups. While no differences in the proportion of sedentary participants were obtained between the three groups, $\chi^{2}=4.52, p=.10$, the groups differed in the proportion of underachievers, $\chi^{2}=7.46, p=.02$, and achievers, $\chi^{2}=13.65, p<.01$. The most favourable adherence pattern could be found in the combined planning group with the lowest percentage of underachievers (11.3\%) and the highest proportion of achievers (71\%). The control and action planning groups did not differ with respect to the percentage of achievers (42\% and $44.1 \%$, respectively). A minor difference in the percentage of sedentary participants (33.3\% in the controls, $26.5 \%$ in the action planning group), indicating an effect of action planning on initiating at least some exercise, remained insignificant, $\chi^{2}=.83, p=.36$.

\section{Gender and age differences}

As a final step, it was tested whether the above-reported findings were confounded with other variables, such as gender and age. Men and women did not differ with respect to baseline measures of behavioural intentions, $F(1,209)=0.04, p=.85$, and exercise, $F(1,209)=0.61, p=.44)$. Men reported higher mean values for cycling (men: $M=63.1, S D=139.9$; women: $M=18.1, S D=49.2 ; F(1,209)=4.60, p=.03$ ). Younger (31-54 years, $N=68$ ), middle-old $(55-64$ years; $N=83$ ), and older patients (65-82 years, $N=60$ ) did not differ on Time 1 measures of intentions, $F(2,208)=1.22$, $p=.30$, cycling, $F(2,208)=1.23, p=.29$, and exercise, $F(2,208)=0.47, p=.63$. 
ANCOVAs on physical exercise and cycling controlling for the baseline, with gender, age and experimental groups as between-subjects factors respectively, were conducted to test differential effects of the experiment on women and men and the different age groups. For exercise, neither gender, $F(1,204)=0.03, p=.87$, nor the interaction between group and gender, $F(2,204)=1.29, p=.28$, yielded significant effects while the main effect group remained highly significant, $F(2,204)=8.11, p<.01$. A similar pattern was found for cycling. Gender, again, had no effect on the change in cycling, $F(1,204)=0.01, p=.93$, and there was no interaction effect, $F(2,204)=0.33$, $p=.72$. The main effect of the experimental treatment remained significant, $F(1,204)=3.10, p=.047$.

Likewise, the main effect for group remained significant when age group was entered as a between-subjects factor, exercise: $F(2,201)=9.76, p<.01$; cycling $F(2,201)=3.13, p=.046$. Furthermore, significant main effects for age indicated that the younger participants reported higher changes in exercise, $F(2,201)=3.70, p=.03$, and cycling, $F(2,201)=3.07, p=.049$, from Time 1 retrospective measures to Time 2 measures. The interaction between age and group was not significant for exercise, $F(4,201)=0.69, p=.60$, nor for cycling, $F(4,201)=2.06, p=.09$

\section{Discussion}

The present study provides evidence that interventions based on action planning and coping planning are useful means to enhance physical activity and adherence in cardiac rehabilitation patients. Despite similar behavioural intentions and other motivational prerequisites, participants who formed action plans in conjunction with coping plans reported more exercise and cycling (as an everyday physical activity) than controls and those who formed solely action plans. The intervention lasted up to 30 minutes and took place on the background of an intensive 3 weeks rehabilitation programme. More than 2 months after discharge, $9 \%$ of the variance in exercise behaviour was accounted for by the experimental treatments. When comparing the control group with the combined planning group, this estimate rises to $12 \%$ explained variance. Given the background of the massive rehabilitation treatment, this documents the effectiveness of a brief planning intervention.

Changes in physical activity could not be attributed to changes in behavioural intentions. These findings provide evidence for the assumption that planning as a postintentional process increases the likelihood of successful behaviour implementation in individuals who are already motivated.

The effects of the experimental treatments remained stable when controlling for gender and age. While gender had no influence on the behavioural change after discharge, younger participants reported higher increases in physical exercise and cycling than older patients.

In contrast to the hypotheses, no significant effects for the action planning treatment alone were found. Although participants who formed action plans reported slightly higher levels of exercise and cycling and lower frequencies of being sedentary (26.5\% vs. 33.3\%) than controls, none of these differences were significant. Based on the findings of this study it can be assumed action planning might not be sufficient for changing habitual behavioural patterns, and it needs to be augmented by other volitional variables, such as coping planning. Action plans need to be shielded against other acquired behavioural tendencies such as habits. Coping planning can facilitate these efforts. By forming coping plans, individuals make use of their life experience by 
anticipating situations in which they are prone to fail at self-regulation, even if they have a precise action plan. It is as yet unclear which strategies are most useful to successfully overcome such situations. Baumeister et al. (1994) state that the process of self-stopping is central to successful self-regulation. The activation of a prepared coping response could therefore be successful just because an existing situation-behaviour association is interrupted. Further research is needed to investigate whether certain strategies are more successful in coping planning than others.

Some methodological issues might have contributed to the lack of significant effect evidenced for action planning. Few studies have investigated the effects of planning interventions over a time period of more than 4 weeks (e.g. Luszczynska \& Schwarzer, 2003; Sniehotta et al., 2005). In a study on exercise participation, Milne et al. (2002) found evidence for the effects of a combined motivational/planning intervention over a 2-week period. On this evidence action planning could be allocated to an early stage in the volitional phase to promote the initiation of a behavioural change, while other constructs, such as coping planning, might be more efficient at later stages of maintenance or recovery. Another characteristic of the present sample is the intensive rehabilitation treatment. Descriptive analyses of the baseline data (see Table 1) show high mean values for intentions. The treatment in the centres as well as the fact that patients had daily experience with bicycle-ergometer training could have resulted in high pre-interventional action planning levels. Therefore, it is possible that the action planning intervention turned out to be less effective than the coping planning intervention because patients had already formed action plans.

The present study has limitations with regard to the validity of the self-report measures for physical activities. Although most of the classical literature on the relation between physical activity and cardiac risk is based on self-report measures, potential biases must be assumed. An advantage of self-report measures compared with observational measures is the opportunity to assess previous behaviour retrospectively by the same method as subsequent behaviour. This allows studying changes in the target behaviour. Nevertheless, it would be fruitful to validate the findings from this study with objective measures in the future, focusing more on the Time 2 measures than on behavioural change.

The present study did not cover a full-factorial design with two independent factors of action planning and coping planning. Since there was no experimental group which formed only coping plans, it cannot be investigated whether the effects of the combined planning group can be attributed to a main effect of coping planning or to an interaction between action planning and coping planning. Nevertheless, the theoretical embedding of coping planning as outlined above presupposes action planning as an integral part of a planning process.

The findings of the present study emphasize the role of volitional processes in adopting and maintaining changes in risk behaviours. Action planning and coping planning in combination have been demonstrated to facilitate adherence to physical activity. Further research, also in other domains of health behaviour change, is needed to study the mediating micro-processes of such changes. In particular, it appears to be worthwhile to study those persons who fail to adhere in spite of good plans.

The findings have implications for cardiac rehabilitation and related programmes that aim for changes in risk behaviours. The presented interventions are brief and they can be incorporated in hospital-based as well as in out-patient rehabilitation programmes. 


\section{Acknowledgements}

The authors are indebted to the patients, staff, and directors of the cooperating rehabilitation centres Brandenburgklinik in Bernau (Dr H. Behr), Klinik am See, Rüdersdorf (Prof. H. Völler), and Klinik Seehof der BfA, Teltow (Dr B. Fuhrmann).

\section{References}

Abraham, C., Sheeran, P., \& Johnston, M. (1998). From health beliefs to self-regulation: Theoretical advances in the psychology of action control. Psychology and Health, 13, 569-591.

Ajzen, I. (1991). The theory of planned behavior. Organisational Bebavior and Human Decision Processes, 50, 179-211.

American Psychological Association (2002). Ethical principles of psychologists and code of conduct. American Psycbologist, 57, 1597-1611.

Armitage, C. J. (2004). Evidence that implementation intentions reduce dietary fat intake: A randomized trial. Health Psycbology, 23, 319-323.

Bandura, A. (1997). Selfefficacy: The exercise of control. New York: Freeman.

Baumeister, R. F, Heatherton, T. F, \& Tice, D. M. (1994). Losing control: How and why people fail at self-regulation. San Diego, CA: Academic Press.

Bernstein, M., Sloutskis, D., Kumanyika, S., Sparti, A., Schutz, Y., \& Morabia, A. (1998). Data-based approach for developing a Physical Activity Frequency Questionnaire. American Journal of Epidemiology, 147, 147-156.

Bjarnason-Wehrens, B., Mayer-Berger, W., Meister, E. R., Baum, K., Hambrecht, R., \& Gielen, S. (2004). Recommendations for resistance exercise in cardiac rehabilitation. Recommendations of the German federation for cardiovascular prevention and rehabilitation. European Journal of Cardiovascular Prevention and Rebabilitation, 11, 352-361.

Campbell, N. C., Thain, J., Deans, H. G., Ritchie, L. D., \& Rawles, J. M. (1998). Secondary prevention in coronary heart disease: Baseline survey of provision in general practice. British Medical Journal, 316, 1430-1434.

Conner, M., \& Armitage, C. J. (1998). The theory of planned behavior: A review and avenues for further research. Journal of Applied Social Psychology, 28, 1430-1464.

Dietz, R., \& Rauch, B. (2003). Guidelines for the diagnosis and treatment of chronic coronary heart disease. Issued by the executive committee of the German Society of Cardiology - Heart Circulation Research in cooperation with the German Society for Prevention and Rehabilitation of Cardiac Diseases and the German Society for Thoracic and Cardiovascular Surgery. Zeitschrift fuer Kardiologie, 92, 501-521.

Gollwitzer, P. M. (1999). Implementation intentions. Strong effects of simple plans. American Psychologist, 54, 493-503.

Gollwitzer, P. M., \& Oettingen, G. (1998). The emergence and implementation of health goals Psychology and Health, 13, 687-715.

Gollwitzer, P. M., \& Sheeran, P. (in press). Implementation intentions and goal achievement: A meta-analysis of effects and processes. Advances in Experimental Social Psychology.

Heckhausen, H. (1991). Motivation and action. Berlin: Springer-Verlag.

Johnston, D. W. (1999). Lifestyle changes after a myocardial infarction. Heart, 82, 243-244.

Kanfer, F. H. (1979). Self-management: Strategies and tactics. In A. P. Goldstein \& F. H. Kanfer (Eds.), Maximizing treatment gains (pp. 185-224). New York: Academic Press.

Lakka, T. A., Venäläinen, J. M., Rauramaa, R., Salonen, R., Tuomilehto, J., \& Salonen, J. T. (1994). Relation of leisure-time physical activity and cardiorespiratory fitness to the risk of acute myocardial infarction in men. New England Journal of Medicine, 333, 2388-2395.

Leon, A. S., Connett, J., Jacobs, D. R., \& Rauramaa, R. (1987). Leisure-time physical activity levels and risk of coronary heart disease and death. The multiple risk factor intervention trial. Journal of the American Medical Association, 258, 2388-2395. 
Leventhal, H., Singer, R., \& Jones, S. (1965). Effects of fear and specificity of recommendation upon attitudes and behavior. Joumal of Personality and Social Psychology, 2, 20-29.

Luszczynska, A., \& Schwarzer, R. (2003). Planning and self-efficacy in the adoption and maintenance of breast self-examination: A longitudinal study on self-regulatory cognitions. Psychology and Healtb, 18, 93-108.

Magnus, K., Matroos, A., \& Strackee, J. (1979). Walking, cycling, or gardening, with or without seasonal interruptions, in relation to acute coronary events. American Journal of Epidemiology, 110, 724-733.

Marcus, B. H., Dubbert, P. M., Forsyth, L. H., McKenzie, T. L., Stone, E. J., Dunn, A. L., \& Blair, S. N. (2000). Physical activity behavior change: Issues in adoption and maintenance. Health Psychology, 19, 32-41.

Milne, S., Orbell, S., \& Sheeran, P. (2002). Combining motivational and volitional interventions to promote exercise participation: Protection motivation theory and implementation intentions. British Journal of Health Psycbology, 7, 163-184.

Morris, J. N., Everitt, M. G., Pollard, R., \& Chave, S. P. W. (1980). Vigorous exercise in leisure time: Protection against coronary artery disease. Lancet, 2, 1207-1210.

O'Connor, G. T., Buring, J. E., Yusuf, S., Goldhaber, S. Z., Olmstead, E. M., Paffenbarger, R. S. Jr, \& Hennekens, C. H. (1989). An overview of randomized trials of rehabilitation with exercise after myocardial infarction. Circulation, 80, 234-244.

Oldridge, N. B., Guyatt, G. H., Fischer, M. E., \& Rimm, A. A. (1988). Cardiac rehabilitation after myocardial infarction: Combined experience of randomized clinical trials. Journal of the American Medical Association, 260, 945-950.

Orbell, S., Hodgkins, S., \& Sheeran, P. (1997). Implementation intentions and the theory of planned behavior. Personality and Social Psycbology Bulletin, 23, 945-954.

Orbell, S., \& Sheeran, P. (1998). Inclined abstainers: A problem for predicting health-related behaviour. British Joumal of Social Psychology, 37, 151-165.

Orbell, S., \& Sheeran, P. (2000). Motivational and volitional processes in action initiation: A field study of the role of implementation intentions. Journal of Applied Social Psycbology, 30 , $780-797$.

Paffenbarger, R. S., Hyde, R. T., Wing, A. L., \& Hsieh, C. (1986). Physical activity, all cause mortality, and longevity of college alumni. New England Journal of Medicine, 314, 603-613.

Pate, R. R., Pratt, M., Blair, S. N., Haskell, W. L., Macera, C. A., Bouchard, C., Buchner, D., Ettinger, W., Heath, G. W., King, A. C., et al. (1995). Physical activity and public health: A recommendation from the Centers for Disease Control and Prevention and the American College of Sports Medicine. Joumal of the American Medical Association, 273, 402-407.

Ronis, D. L., Yates, J. F, \& Kirscht, J. P. (1989). Attitudes decisions and habits as determinants of repeated behavior. In A. R. Pratkanis, S. J. Breckler, \& A. G. Greenwald (Eds.), Attitude structure and function (pp. 213-239). Hillsdale, NJ: Erlbaum.

Schwarzer, R. (1992). Self-efficacy in the adoption and maintenance of health behaviors: Theoretical approaches and a new model. In R. Schwarzer (Ed.), Self-efficacy: Tbought control of action (pp. 217-242). Washington, DC: Hemisphere.

Schwarzer, R., \& Renner, B. (2000). Social-cognitive predictors of health behavior: Action selfefficacy and coping self-efficacy. Health Psychology, 19, 487-495.

Sheeran, P.(2002). Intention-behaviour relations: A conceptual and empirical review. In W. Stroebe \& M. Hewstone (Eds.), European review of social psychology (Vol. 12, pp. 1-36). Chichester, England: Wiley.

Sheeran, P., \& Orbell, S. (2000). Using implementation intentions to increase attendance for cervical cancer screening. Health Psychology, 19, 283-289.

Sniehotta, F. F, Scholz, U., \& Schwarzer, R. (2005). Bridging the intention-behavior gap: Planning, self-efficacy, and action control in the adoption and maintenance of physical exercise. Psycbology and Health, 20, 143-160. 
Sniehotta, F. F, Schwarzer, R., Scholz, U., \& Schüz, B. (2005). Action planning and coping planning for long-term lifestyle change: Theory and assessment. European Journal of Social Psychology, 35, 565-576.

Sutton, S. R. (1994). The past predicts the future: Interpreting behaviour-behaviour relationships in social-psychological models of health behaviours. In D. R. Rutter \& L. Quine (Eds.), Social psychology and bealth: European perspectives (pp. 47-70). Aldershot, England: Avebury.

Thomson, P. D., Buchner, D., Piña, M. D., Balady, G. J., Williams, M. A., Marcus, B. H., Berra, K., Blair, S. N., Costa, F, Franklin, B., Fletcher, G. F, Gordon, N. F, Pate, R. R., Rodriguez, B. L., Yancey, A. K., \& Wenger, N. K. (2003). American Heart Association Council on Clinical Cardiology Subcommittee on Exercise, Rehabilitation, and Prevention; American Heart Association Council on Nutrition, physical activity, and metabolism subcommittee on physical activity exercise and physical activity in the prevention and treatment of atherosclerotic cardiovascular disease. Circulation, 107, 3109-3116.

Willich, S. N., Müller-Nordhorn, J., Kulig, M., Binting, S., Gohlke, H., Hahmann, H., Bestehorn, K., Krobot, K., \& Völler, H. (PIN Study Group), (2001). Cardiac risk factors, medication, and recurrent clinical events after acute coronary disease; a prospective cohort study. European Heart Journal, 22, 276-279.

World Health Organization (WHO) Expert Committee (1993). Rebabilitation after cardiovascular disease with special emphasis on developing countries (Tech. Rep. Series 831). Geneva: Author.

Ziegelmann, J. P., Lippke, S., \& Schwarzer, R. (in press). Adoption and maintenance of physical activity: Planning interventions in young, middle-aged, and older adults. Psychology \& Health. 